\title{
Previsão da produção bovina na rodovia Transamazônica do Brasil
}

\author{
Philip M. Fearnside $\left({ }^{*}\right)$
}

\begin{abstract}
Resumo
O governo brasileiro está atualmente promovcndo o desenvolvimento de pastagens para gado em vastas áreas da Bacia Amazônica, por meio de um programa de incentivos fiscais e tributários. Este fato tem sido encorajado por declaraçōes recentes, de que as pastagens melhoram a qualidade dos solos, possivelmente podendo propiciar uma produção bovina por tempo indeterminado. Cálculos da produtividade bovina prevista para áreas, como as adjacentes à rodovia Transamazônica, feitas por vários métodos, levam à conclusāo que as expectativas sāo demasiadamente otimisticas. O presente trabalho desenvolve equações para a previsão de produção de gado, numa área de estudo ao longo da Transamazônica, levando em consideração os efeitos dos nutrientes do solo e a competiçâo com plantas invasoras. Niveis baixos de fósforo no solo e a invasão de ervas não comestiveis reduzem a produçāo de gramineas e, consequientemente, de gado, a niveis muito baixos. Apresenta-se os resultados de uma simulação por computador acerca da produção de gado baseada tanto nas relações desenvolvidas ligando as produções a nutrientes do solo e a invasoras, quanto nas informações sobre solos colhidas na área de estudo na Transamazônica. A simulação das pastagens é parte de uma simulação maior do agro-ecossistema dos colonos da Transamazônica, cujo objetivo é estimar a importância de vários fatores na capacidade de suporte dessa área, para populaçōes humanas. Embora o estudo da capacidade de suporte mostre que a agricultura baseada principalmente em culturas anuais apresente grandes riscos, coloca também em dúvida a pressuposição de rendimentos seguros e contínuos, pelos projetos de desenvolvimento de pastagens promovidos atualmente na Amazônia brasileira.
\end{abstract}

\section{INTRODUÇÃo}

Esta previsão da produção ganadeira na rodovia Transamazônica é parte de um estudo visando a estimativa da capacidade de sustentação de populações humanas em uma parte da área de colonização nas proximidades de Altamira, Pará (Fearnside, 1978). Os métodos de previsão de produção bovina aqui discutidos, quando combinados com a previsão de mudanças da fertilidade do solo usado para pastagens (Fearnside, $\mathbf{s} / \mathrm{d} b$ ), permitem a simulação da produção de gado, ou como parte do modelo "KPROG2" para a capacidade de suporte humana, ou separadamente, em uma simulação menor para produções de culturas individuais e mudanças no solo, chamado "AGRISIM". Sub-rotinas tratando da produção ganadeira e mudanças nos solos sob pastagem são incluidas no programa e documentação para KPROG2, junto com uma lista completa de va. lores dos parâmetros usados em execuçōes padrōes do modelo (Fearnside, $s / d a$ ). As seguintes questões, muito debatidas no Brasil, tornam esse assunto particularmente atual : 1) É sustentável, indefinitivamente, a fertilidade do solo usado para pastagem?; 2) Isso implica em que a produção bovina seja também sus. tentável?; 3) Deve-se concluir disto que vas tas áreas da Bacia Amazônica devam ser trans. formadas em pastagens? As descobertas de Falesi $(1974,1976)$, de que as pastagens melhoram a fertilidade do solo, vieram fortalecer o maciço programa de incentivos fiscais do governo brasileiro, encorajando a rápida conversão de grande parte da Amazônia em áreas de pastagens. A discussão sobre solos e pastos foi feita em um estudo à parte sobre as mudanças da fertilidade do solo sob pastagem (Fearnside, s/db). A importância desse debate faz com que a questão da previsão de produção ganadeira seja examinada cuidadosamente. Tendo isto em mente, o presente trabalho apresenta várias maneiras possiveis de calcularem-se as previsões de produção de gado, com base primeiramente em informaçōes isoladas, agrupadas a partir da bibliografia sobre o assunto, e em meus próprios estudos na rodovia Transamazônica realizados em dois anos de trabalho de campo na área (1974-1976), mais visitas curtas que estendem o período de informaçōes de 1973 até 1978 . Todos os métodos de cálculo levam à conclusão de que as

(*) - Instituto Nacional de Pesquisas da Amazônia, Manaus: 
produções de gado a serem esperadas estão muito abaixo das projeções oficiais para a Amazônia e que, por vários motivos, não se pode pretender que essas produçōes permanecam pelos longos períodos sugeridos pelas afirmativas oficiais (Fearnside, 1979).

\section{LOTAÇÃO POR HECTARE E "CAPACIDADE}

DE SUPORTE" DAS PASTAGENS

Encontram-se numerosas declarações na bibliografia sobre o assunto, atribuindo valores para a "capacidade de suporte" das terras firmes na Amazônia. A maioria dessas afirmações não são acompanhadas por dados básicos mostrando como as figuras foram deriva. das. Presumivelmente, a maior parte delas são resultantes de observaçōes (apesar de não especificarem a amostragem quanto ao tamanho, método, etc.) do número de cabeças de gado por hectare, na realidade colocados nas pastagens pelos fazendeiros na época da entrevista. Isto, naturalmente, não é realmente uma estimativa da "capacidade de suporte". pois não há indicações de que, por exemplo, através de observações das mudanças nas populações de plantas invasoras ou no solo, os dados de lotação por hectare observados pudessem ser mantidos em uma base sustentá. vel. Em novas áreas, como as próxinıas à Transamazônica, os dados de lotação por hectare podem ser enganosos, pois o número de cabeças é geralmente baixo devido à falta de disponibilidade de gado ou dinheiro para adquirilo, em vez de qualquer convicção, por parte do fazendeiro, de que o aumento da lotação por hectare causaria a deterioração da pastagern Há também o problema de imprecisão quanto ao aspecto dos dados de lotação por hectare referirem-se à densidade do rebanho na área que na realidade está sendo usada como pasto no período da entrevista, ou se os dados se referem a áreas mais extensas, incluindo terras em pousio, entre períodos de uso como pastagem. A inclusão destas últimas pode significar uma diferença de um fator de 3 ou 4 , como é o caso de operações em duas propriedades na parte amazônica do Peru, em que foram registrados os 2 tipos de cálculo da lotação por hectare: Tournavista com 3 cabeças por hectare de pastagem em uso e 1 cabeça/ nectare na área global; Granja San Jorge, com 1,5 cabeças/hectare de pastagem em uso e 0,4 cabeça/hectare na área global (Watters, 1971). As seguintes citaçōes sobre a "capacidade de suporte" de gado na terra firme amazonica, apresentam a variedade de opiniōes : 1) o representante brasileiro na conferência sobre o desenvolvimento de tazendas de gado na America Tropical Úmida, realizada em Guayaquil, Equador, em 1973, escreveu que a "capacidaae média de suporte" é uma cabeça por 2,5 hectares/ano $(0,40$ cabeça/hectare) (Nascimento \& Moura Carvalho, 1973: III-B-32); 2) O diretor da EMBRAPA-IPEAN (atualmente CPATU) em Belém, escreveu que "a capacidade de suporte pode atingir 4 cabeças/ha." no que ele descreve como "pastagens magníficas" nas proximidades de Paragominas, Pará (Falesi, 1974: 2.14); 3) A "capacidade de suporte" das plantações experimentais de Brachiaria decumbens na EMBRAPA-IPEAN em Belém é estimada em 1,5 cabeça/hectare/ano baseada em "dados iniciais quantitativos e qualitativos, e observaçōes em vários anos" (Serrão \& Neto, 1971: 26); 4) Usando dados do número total do rebanho e a área total de pastagens na região Norte do Brasil (que inclui tanto a várzea como a terra firme), a EMBRAPA dá o valor de 2,7 hectares/cabeça $(0,37$ cabeça/hectare $)$ num relatório do Projeto Nacional de Bovinos (Barcellos, 1974); 5) A Superintendência do Desenvolvimento da Amazônia (SUDAM) num documento básico para seu programa de incentivos fiscais para pastagens, dá 1 cabeça/hectare como a "capacidade de suporte" de áreas florestais para criação e 2 cabeça/hectare para a engorda (SUDAM, Departamento de Incentivos, 1974); 6) Nigel Smith estima que a "capacidade de suporte" na terra firme amazônica é 1 cabeça/hectare, baseado em entrevistas sobre lotações por hectare em quatro fazen. das (Smith, 1977).

CÁlCUlo da " CAPACidAde DE alimentação para TRÊS ANOS" PARA PASTAGENS NA TRANSAMAZÔNICA

PRODUTIVIDADE DAS PASTAGENS

SOB CONDIÇÕES MÉDIAS

Considerando que não se tem disponibilidade de informaçōes suficiente para calcular 
a "capacidade de suporte" das pastagens que inclua uma tolerância para mudanças a longo prazo decorrentes do domínio de plantas invasoras e compactação do solo, pode-se estimar algo que poderia ser denominada de "capacidade de alimentação para 3 anos" com base em uma variedade de informações encontradas na bibliografia.

A proautividade anual de peso seco para os pastos sob diterentes condiçoes de soio, tem que ser conhecida para que a capaciaade ue alımentaçao dos pastos na Iransamazonica russa ser estımada. Esses dados devern rtsuitar de uma variedade de experienncıas reaızadas na Transamazönica e em Belem, consicerando que anteriormente não foi teıta nenhuma experiência que fornecesse a medida necessária. Quase todas as pastagens ao Iongo da Transamazônica são de capim coloniao (Panicum maximum). Dados locais para estimar a produtividade dessas pastagens não sao disponiveis, pois, as experiências realizadas até o momento são ensaios de variedades utilizando canteiros adubados. Dados dessas experiências locais podem ser usados para uma estimativa grosseira da diferença de produçäo entre essa e uma outra variedade (Brachiaria decumbens Stapf) para a qual existe maior quantidade de dados. Panicum maximum produz melhor que Brachiaria decumbens por um fator de 1,12 (Viégas \& Kass, 1974). Nessas experiências, apesar de fertilização com superfosfato, sulfato de amônia, cloreto de potássio e esterco orgânico, a espécie Panicum maximum foi descrita como apresentando "desenvolvimento vegetativo pouco satisfatório com visiveis sintomas de deficiência nutricional" (Viégas \& Kass, 1974). Além da adubação, observei esses ensaios no melhor tipo de solo da área, a terra roxa - ALFISOL (o relatório, que foi escrito na sede em Belém, está aparentemente errado quando afirma que o solo era do tipo menos fértil, podzólico vermelho amarelo -- ULTISOL) (Viégas \& Kass, 1974).

Se a diferença relativa de produção entre as duas variedades puder ser considerada como mantida em solos de fertilidade mais bai$x a$, pode-se ter uma noção da produtividade de Panicum maximum na área de Altamira, com base no comportamento de Brachiaria decum. bens, em Belém. As experiências em Belém foram feitas em um tipo diferente de solo (latossolo amarelo-ULTISOL), mas os niveis dos vários nutrientes são similares aos encontrados no podzólico vermelho amarelo, o tipo de solo mais comum na "área de estudo intensivo" da Rodovia Transamazônica que foi o foco dos meus estudos sobre a capacidade de suporte de populaçōes humanas na área (Fearnside, 1978). Os nutrientes do solo, para a área de experiência em Belém, são dados como : $\mathrm{Al}+++=1,2 \mathrm{meq} / 100 \mathrm{~g}, \mathrm{Ca}++\mathrm{e} \mathrm{Mg}++=$ $0,59 \mathrm{meq} / 100 \mathrm{~g}, \mathrm{P}=4,0 \mathrm{ppm}$ e $\mathrm{K}=40,0 \mathrm{ppm}$ (Nota : o relatório (Serrão et al., 1971) dá as unidades para P e K como " $\mathrm{kg} / \mathrm{ha"}$ ", mas a inconstância com os dados em outros lugares no relatório, mais o conhecimento de como os resultados de análise de solo da EMBRAPA são divulgados, leva-me a crer que as unidades sejam, na realidade, ppm). As experiências em Belém mostram o valor de $253 \mathrm{~kg} / \mathrm{ha}$ para a produção da Brachiaria (Peso do capim seco) em canteiros não fertilizados, para os primeiros 342 dias, e que corresponderia a aproximadamente $270 \mathrm{~kg} / \mathrm{ha}$ para um ano de 365 dias. Corrigindo este dado para a diferença de variedade, uma estimativa de $303 \mathrm{~kg}$ (peso se$\mathrm{co}$ /ha pode ser feita para o primeiro ano de produção de Panicum maximum.

A produção das pastagens, após o primeiro ano, declina acentuadamente, principalmen te devido a penetração de plantas invasoras. O problema das invasoras é maior em solo de menor fertilidade. Isto é mostrado pela comparação da porcentagem de plantas invasoras no peso seco total de vegetação como opostas à pastagem em experiências realizadas em áreas de Brachiaria em solos de diferentes níveis de fertilidade (Serrão et al., 1971). Os pesquisadores de Brachiaria concluem que a menor fertilidade torna impossivel às pastagens, competir efetivamente com as plantas invasoras que são adaptadas às condições de baixa fertilidade. Em canteiros não fertiliza dos de Brachiaria decumbens, após 404 dias, $83 \%$ do peso seco é constituído por invasoras e, em terrenos de B. ruziziensis, depois de 368 dias, $73 \%$ do peso seco é constituido de invasoras (Serrão et al., 1971). Éstes dados contrastam com as porcentagens de 10 e $0 \%$ de 
invasoras em canteiros que sofreram um tratamento completo de fertilização. Poder-se-ia esperar invasões ainda maiores de plantas em pastagens ocupadas pelo gado, pois este, seletivamente, iria se alimentando do capim e não das invasoras. Deixando de lado os efeitos de uma maior invasão em pastagens de solo menos fértil e os efeitos do gado, pode-se pelo menos conseguir um dado mínimo sobre o de. clínio de produção de pastagens após o primeiro ano, com base nos resultados de outra experiência realizada com a Brachiaria, num período de 3 anos, em Belém. Aqui os canteiros foram fertilizados anualmente com adubo quimico e orgânico e foram carpidos uma vez durante 0 ano. Os resultados apresentados por Panicum maximum no segundo ano é de $63 \%$ do rendimento do primeiro ano, e no terceiro ano é de $40 \%$ do rendimento do primeiro (Si. mão Neto et al., 1973).

Usando os resultados das experiências aci. ma mencionadas como estimativa do declínio de rendimento após o primeiro ano, os 303,0 $\mathrm{kg} / \mathrm{ha}$ (peso seco) de produçāo no primeiro ano diminuiriam para $190,9 \mathrm{~kg} /$ ano no segundo e $148,5 \mathrm{~kg} /$ ano no terceiro. Isso daria uma produtividade média da pastagem de $214,1 \mathrm{~kg} / \mathrm{ha} /$ ano (peso seco), num período de três anos para solos não fertilizados, para esta área de solos representativos. Considerando que a maioria das estimativas que foram necessárias fazer na derivaçăo deste valor são do lado otimista, a produtividade real de gramíneas poderá ser menor que a apresentada pelos dados acima.

\section{PRODUTIVIDADE DE CARNE BOVINA}

Valores aproximados, para a conversão de peso seco do capim em carne bovina, podem ser tirados do modelo de um sistema de criação de gado africano delineado por Odum (1971). Odum usa o valor de $4,5 \mathrm{kcal} / \mathrm{g}$ de peso seco para a energia contida pela pastagem e o valor de $8.000 \mathrm{kcal} / \mathrm{dia}$ como a necessidade metabólica de um boi de 294,8 kg (citando Kleiber, 1961 para o último dado). Isto é equivalente a $27,13 \mathrm{kcal} / \mathrm{kg}$ de peso vivo/dia, ou $2,20 \mathrm{~kg}$ de peso seco de pasto/kilo de peso vivo/ano.
O peso médio de abate para gado de corte na Amazônia é considerado $330 \mathrm{~kg}$ por Nascimento \& Moura Carvalho (1973: III-B-32), e $350 \mathrm{~kg}$ por Smith (1977), citando dados de F.A.O. (1973) e do Instituto do Desenvolvimento Econômico-Social do Pará (Brasil, IDESP, 1970). A idade média de abate é consicierada 4 anos em todas essas referências e 4,5 a 5,6 anos no relatório da EMBRAPA (Barcellos, 1974).

Usando-se o valor de $330 \mathrm{~kg}$ como o peso de abate para gado "adulto", o peso seco/kcal e os dados de metabolismo usados por Odum podem ser utilizados para calcular a quantidade de peso seco de pastagem necessária pa ra manter uma cabeça de gado por ano, resultando no valor de $726,8 \mathrm{~kg}$ peso seco/cabeça/ ano. Por falta de outros dados, supōe-se que esta taxa de consumo resultaria na taxa de crescimento médio que levaria o gado a atingir o peso de abate de $330 \mathrm{~kg}$ em 4 anos. De uma maneira otimista, se supursermos que o gado possa comer todo o capim produzido, a "capacidade de alimentação" no primeiro ano seria $303 \mathrm{~kg}$ de peso seco produzido divididos pelos $726,8 \mathrm{~kg} /$ cabeça/ano, ou seja 0,42 cabeça/ha para o primeiro ano. A "capacidade de alimentação" no segundo e terceiro ano. seria respectivamente, 0,26 e 0,21 cabeça/ha. A capacidade de alimentação para 3 anos seria portanto 0,30 cabeça/ha.

Existem várias alternativas quanto aos fatores de conversão dos dados da produção em "capacidade de suporte" ou estimativas de produção de carne, disponíveis na bibliografia. Elas levam entretanto, a quase exatamente os mesmos resultados que os fatores de conversão usados por Odum.

Um método alternativo pode ser deduzido dos cálculos de Vicente-Chandler (1975). Segundo ele, a "capacidade de suporte" para um novilho de $273 \mathrm{~kg}$ é dada como equivalente a $3,86 \mathrm{~kg}$ de nutrientes totais digeriveis por dia. Os nutrientes totais digeríveis foram calculados para um $\mathrm{kg}$ de forragem seca formada de capim estrela (Cynodon plectostachyum) e capim pangola (Digitaria decumbens), usando o valor de $0.54 \mathrm{~kg}$ de nutrientes totais digeriveis como igual a um $\mathrm{kg}$ de pastagem seca. O método realmente usado pcır Vicente-Chandler é 
o reverso, como é comum na bibliografia de manejo pecuária : os aumentos de peso do gado são medidos e são calculados as quantidades de nutrientes totais digeriveis e a matéria seca que deve ter sido comida. Usando estes valores seria necessário $9,56 \mathrm{~kg}$ de peso seco de pastagem $/ \mathrm{kg}$ de peso vivo de gado por ano Tem que ser deixado de lado aqui o problema da pastagem plantada em solos deficientes em minerais, tais como fósforo, serem menos nutritivas do que os pesos equivalentes de pastagem plantada em solos mais férteis (Kamprath, 1973). A capacidade de alimentação para novilhos de $330 \mathrm{~kg}$, usando os valores de produção anteriormente estimados para as pastagens da Transamazônica sob condições médias, seria de 0,37 cabeças/ha para o primeiro ano, 0,26 cabeças/ha para o segundo ano, e 0,20 cabeças/ha para o terceiro ano. Isto resulta em uma média para a capacidade de alimentação por três anos de 0,28 cabeças/ha.

Um terceiro método de cálculo também produz um valor semelhante. Uma estimati. va da capacidade de alimentaçăo pode ser feita a partir da taxa de peso adquirido para que na idade média de abate de quatro anos fossem atingidos $330 \mathrm{~kg}$, emparelhando a um fator de conversāo que relacione as quantidades digeridas às adquiridas. Vicente-Chandler (1975) emprega uma fórmula utilizando pesos de corpo, dias de pastoreio e pesos adquiridos para fazer o cálculo reverso a partir dos pesos adquiridos para a quantidade comida. Ele não forneceu a fórmula, mas a atribui ao "Comitê de Pesquisa da Pastagem (1943)" sem apresentar citaçāo bibliográfica. De 17 de tais conversōes feitos no artigo de Vicente-Chandler os fatores de conversão estão todos quase juntos à média de $0,14 \mathrm{~kg}$ de peso adquirido/ $\mathrm{kg}$ de nutrientes digeriveis consumidos (a variação é $0,12-0,16, D P=0,01$ ). Usando o fator de conversão de 0,54 para converter matéria seca em nutrientes totais digeríveis, pode-se estimar a $187 \mathrm{~kg} / \mathrm{ha}$ a produção anual média de nutrientes totais digeriveis no decorrer de um período de 3 anos. O peso potencial adquirido pelo gado a partir disto, supondo que o gado tenha comido todo o capim, é então de $26,2 \mathrm{~kg}$ de peso adquirido/ha/ano em média para os três anos. Desde que um novi-
Iho tem que adquirir uma média de $82,5 \mathrm{~kg} / \mathrm{ano}$ a fim de atingir o peso de $330 \mathrm{~kg}$ em quatro anos, a capacidade de alimentação por três anos pode ser estimada em 26,2 dividido por 82,5 , ou seja 0,32 cabeças/ha.

Não constitui surpresa o fato de que o valor de 0,32 cabeças/ha, a partir do peso adquirido, esteja próximo tanto do valor 0,30 cabeças/ha derivado das conversōes de calorias de Odum quando do valor de 0,28 cabeças/ha derivado do fator de conversăo "capacidade de suporte" de Vicente-Chandler. O fato de que esses valores de "capacidade de alimentaçăo por três anos" sejam mais baixos do que a maioria das taxas de lotaçăo por hectare, acentua a crítica em se usar a taxa de lotação como uma estimativa da "capacidade de suporte" da pastagem.

Os três anos de capacidade de alimentação das pastagens deveriam corresponder a grosso modo à taxa máxima de lotação por hectare que pagariam na base de curto termo pela pastagem do tipo que inclui tanto às áreas de pasto que estão realmente em uso em qualquer ponto no tempo quanto pastagens de onde o gado foi temporariamente excluido para permitir recrescimento, mas não áreas de capoeira que vāo se recuperando entre períodos de uso como pastagem. Uma taxa de lotação por hectare deveria ser mais baixa do que esta se o fazendeiro estivesse preocupado com a prevenção contra degradação de pastagens, assim como da produção máxima a curto prazo.

\section{Ciclos prováveis de MANeJo de PASTAGem NA RODOVIA TRANSAMAZÔNICA}

A pergunta sobre o que acontece à produção de pastagem após o terceiro ano permanece. Minhas entrevistas com fazendeiros da antiga área de colonização na regiāo ao norte de Altamira, que tinha sido colonizada bem antes da construção da rodovia Transamazônica, revelaram que as pastagens săo queimadas aproximadamente a cada três ou quatro anos depois da exclusão de gado por uns poucos meses. Elas são deixadas em capoeira por períodos mais longos, altamente variáveis. Capins de pastagem tais como Jaraguá (Hyperrhenia rufa Nees Etapf) e mais tarde o Colonião 
(Panicum maximum) somente apareceram na região de Altamira depois de 1968. Esses capins têm tornado possivel manter às áreas em pastagem sem repouso por períodos mais longos do que era possível anteriormente, quando as únicas variedades disponiveis tinham de ser plantadas por mudas ao invés de semen tes; eram muito sensíveis à estiagem no período após a queimada e só duravam quatro a cinco anos antes que fosse necessário um período de repouso em capoeira. Mesmo com capins resistentes, tais como Panicum maximum, os períodos de repouso parecem ser o melhor modo de se tratar o crescimento inexorável das populações de ervas daninhas. Numerosas pastagens podem ser observadas retornando a crescimento secundário lenhoso tanto na rodovia Transamazônica como na rodovia Belém-Brasilia. Também, vi diversas pastagens velhas (com datas de derrubada de 1912 até 1955) perto de Altamira que nāo tinham repousado durante muitos $(10-20)$ anos e que agora foram completamente invadidas por hortelã (Lamiaceae) não comestível. Estas pastagens também tẽm o solo duro extremamente compactado. O processo de compactação do solo sob pastagem e as taxas de recuperação sob capoeira são discutidos separadamente (Fearnside, 1978).

O manejo da pastagem pode ser considerado como uma resposta a três tipos de ciclos de degradação-regeneração. Primeiro existe uma degradação a curto prazo resultante da remoção do capim através de pastoreio e da invasão de algumas ervas daninhas baixas. Isto pode ser combatido afastando o gado da pastagem periodicamente durante um mês ou dois, usando um sistema de rotação entre subdivisōes cercadas na fazenda. Isto permite o recrescimento do capim e expulsão das ervas daninhas. Segundo, existe uma degradação a meio tempo resultante da invasão de capoeira lenhosa. Isto requer a queimada da pastagem, ou pelo corte da capoeira e queimada da pastagem a cada três ou quatro anos, ou deixando a pastagem em um período curto de repouso em capoeira seguido de roçada e queimada. Um terceiro tipo de degradação é uma possível deterioração a longo prazo dos níveis de nutrientes e da estrutura do solo. Perío- dos muito longos de repouso seriam necessá rios para conter este tipo de degradação.

A questão importante com respeito ao repouso da terra da pastagem não é a đé coin que freqüência ou por quanto tempo um colono deve colocar sua terra em repouso, mas a de com que freqüência e por quanto tempo ele irá realmente fazer isto. Existe pouca justiticativa para esperar que sua decisão seja ba. seada na consideração de benefícios a longo prazo, ao invés de uma imediata comparaçao do valor da produção de carne a partir da manutenção de uma certa área de terra em pástagem por um ano a mais versus o trabalho requerido para controlar as ervas daninhas invasoras. Desde que dados adequados sobre tal comportamento não estão disponiveis, devemos nos contentar somente com uma estimativa grosseira de qual período de pastoreio ou repouso é mais provável. Minha sugestão é a de um período de pastoreio de aproximadamente cinco anos. Um período de repouso de um mínimo de dois anos seria necessário para permitir um suficiente recrescimento que facilitasse a roçagem. Tal repouso curto, entretanto, somente poderia ser seguido pelo uso como pastagem, uma vez que um periodo mais longo de repouso de, digamos, cinco anos, provavelmente seria necessário para permitir que as sementes de capim no solo morressem caso o colono desejasse plantar culturas anuais seguindo a roçagem e queima da capoeira. A extensão real do tempo em que uma área de terra é deixada em repouso, além desses valores mínimos estimados, dependeria da quantidade de trabalho disponível ao colono depois de alocar o seu esforço para quaisquer outras tarefas de prioridade mais alta.

Alguém pode somente conjeturar as produções de pastagem em peso seco que poderiam ser esperadas no quarto e quinto anos, desde que houvessem influências competidoras operando a partir do melhoramento resultante da queimada e da contínua deterioraçăo causada pela invasão de ervas daninhas, assim como a compactação do solo e outros problemas. Por falta de outros dados, podemos fazer uma suposição provavelmente otimista da produtividade contínua ao nível do terceiro ano durante o quarto e quinto anos. Usando a estimativa 
do terceiro ano a partir do valor de Odum, teríamos dois anos adicionais de capacidade de alimentação a 0,21 cabeças/ha, o que abaixaria a média da capacidade de alimentação por cinco anos para 0,26 cabeças/ha. Se o período mais curto de dois anos de repouso fosse também incluído, então a capacidade média de alimentação para o ciclo de sete anos seria ainda mais reduzida a 0,19 cabeças/ha.

\section{Previsão DA PRODUÇÃo DA PASTAGEM A} PARTIR DA FERTILIDADE DO SOLO

Experimentos de adubação com gramíneas forrageiras tornaram claro que se espera grandes diferenças na produtividade conforme a fertilidade do solo, independentes de quaisquer outros problemas tais como invasão das ervas daninhas e compactação do solo. Nos experimentos de adubação feitos com Brachiaria, em Belém, descobriu-se que a adubaçăo fosfatada teria o maior efeito na produtividade, seguida pelo potássio (Serrão et al., 1971). Os niveis de fósforo na rodovia Transamazônica são muito baixos, usualmente (mas não sempre) menores do que os valores relatados para os canteiros adubados em Belém, logo, as relações entre fósforo e produção achadas em Belém pode ser aplicáveis à rodovia Transamazônica. Precisa-se supor que o Panicum maximum usado na rodovia Transamazônica responda ao fósforo da mesma forma que a Brachiaria decumbens usada nos experimentos. Respostas bem positivas ao fósforo pelo Panicum maximum foram obtidas em Paragominas, Pará (Koster et al., 1977).

Podemos esperar que a resposta da pastagem ao fósforo siga o mesmo padrão de linear com "plateau" ("Linear Response Plateau") característico da maioria das culturas, para estimar o valor crítico para o fósforo do solo, acima do qual aumentos na produção não poderiam ser esperados; foram usados os resultados de um experimento diferente de fertilização da Brachiaria decumbens, feito na zona de cerrado do Brasil. As produções de matéria seca a três níveis, de quatro diferentes fertilizantes fosfatados, foram estimadas a partir do gráfico da resposta a níveis diferentes de fertilização (North Carolina State University. Soil Science Department, 1974: 198). Estes valo. res de produção foram colocados em gráficos, em relação com niveis de fósforo do solo, a partir de amostras que tinham sido tomadas por volta do meio do período experimental (North Carolina State University. Soil Science Department, 1974: 101). Os niveis críticos do fósforo do solo foram estimados graficamente por meio do uso do método "Linear Response Plateau", descrito por Waugh et al., (1975). Os valores críticos para dois dos tipos de fertilizantes foram estimados em $10 \mathrm{ppm}$, um terceiro tipo em $17 \mathrm{ppm}$, e um quarto tipo em 22 ppm. O valor mais otimista de $10 \mathrm{ppm}$ (correspondente a uma resposta mais intensa ao tósforo) foi escolhido para a estimativa das respostas do Panicum maximum em Altamira. Uma concentração "ótima" de fósforo de 25 ppm para Panicum maximum foi encontrada em um experimento em Puccalpa, Peru, mas este valor não foi usado uma vez que o solo foi descrito como um solo raro, com capacidade excepcionalmente baixa de fixaçăo do fósforo (North Carolina State University. Soil Science Department, 1974).

Estimei a relação entre produções de pastagem e níveis de fósforo do solo usando os dados extraídos de resultados de experimentos de adubação de Brachiaria feitos em Belém (Serrão et al., 1971). Nos experimentos com Brachiaria, as amostras do solo foram tomadas na ocasião de cada um dos oito cortes relatados, e os valores aproximados para fósforo puderam ser tomadas a partir dos gráficos apresentados no relatório. A produção de peso seco de capim do canteiro que recebeu um tratamento completo de fertilizantes pode ser comparada com a do canteiro que recebeu o tratamento completo menos o fósforo. O terreno que não recebeu fósforo pela adubação teve os níveis de fósforo do solo constantes no decorrer do experimento em cerca de $2 \mathrm{ppm}$, enquanto que as concentrações no canteiro com o tratamento completo variaram de 2 até $15 \mathrm{ppm}$. Se calcularmos a produção de cada corte para o canteiro que recebeu fósforo adicional como uma proporção da produçấo para aquele corte no canteiro sem fósforo adicional, podemos ver uma tendência ligando os indices mais altos de fósforo às produções mais altas. 
Usando o valor crítico estimado de fósforo de $10 \mathrm{ppm}$ como o início da parte plana da curva de resposta, se pode fazer uma regressão sobre os valores das oito produções. Aos níveis de fósforo acima de $10 \mathrm{ppm}$ foram designados valores de $10 \mathrm{ppm}$ como seria previs. to a partir do modelo de "Linear Response Pla. teau". Todos os valores de fósforo foram en. tão convertidos a valores de fósforo em excesso das $2 \mathrm{ppm}$ no canteiro testemunho (aqui o canteiro completo menos fósforo), e todas as produções foram expressas como proporções do testemunho com um excesso de 1,0. Estas manipulações permitiram que a regressão fosse forçada através da origem. A re. gressāo é apresentada na Tabela 1.

TABELA 1 - Regressão da produção da pastagem so. bre fósforo.

\begin{tabular}{|c|c|}
\hline Riegressão & $4,84 \mathrm{~A}$ \\
\hline Erro Padräo & 1,27 \\
\hline t estatístico & 3,82 \\
\hline Significância & $<0,01$ \\
\hline Correlação Parcial & 0,82 \\
\hline R. Quadrado $=0,44$ & F estatístico $=14,55$ \\
\hline $\mathrm{N}=8$ & \\
\hline
\end{tabular}

Abreviaturas: $Y=$ (produçōo com fósf́oro/produçāo sem fósforo) $-1,0$

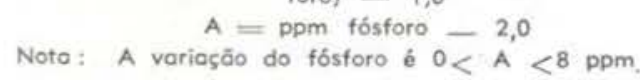

As equações resultantes para previsão da produçăo da pastagem a partir do fósforo do solo são as seguintes :

$\mathrm{Y}=\mathrm{B}(4,84 \mathrm{P}-8,68) \mathrm{W}_{t}$ para $\mathrm{P}<10 \mathrm{ppm}$

$\mathrm{Y}=39.72 \mathrm{~B} \mathrm{~W}_{\mathrm{t}} \quad$ para $\mathrm{P} \geq 10 \mathrm{ppm}$

onde :

$\mathrm{Y}=$ produção da pastagem em $\mathrm{kg}$ de peso seco/hectare/ano.

B = produção base (produção esperada do primeiro ano em $\mathrm{kg}$ de peso seco/hectare para a variedade a $2 \mathrm{ppm}$ de fósforo.
$W=$ fator ano (diminuição proporcional a partir da produção do primeiro ano devido à invasão de ervas daninhas). Os valores são:

$$
\begin{aligned}
& \mathrm{W}_{1}=1,00 \quad \mathrm{~W}_{2}=0,63 \quad \mathrm{~W}_{3}=0,49 \\
& \mathrm{t}=\mathrm{o} \text { ano. }
\end{aligned}
$$

A figura 1 apresenta os dados a partir da regressão da Tabela 1, mostrando o efeito do fósforo, com ajustamento apropriado dos eixos para expressar a produção como uma proporção da produção não fertilizada (fósforo 2 ppm) e o nível de fósforo em ppm.

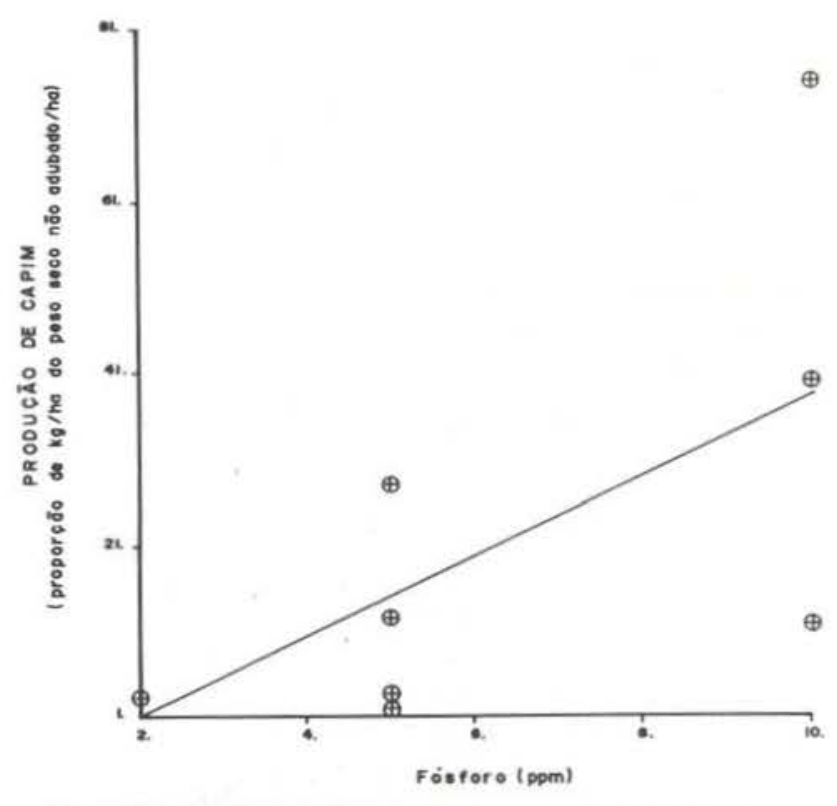

Fig. 1-Regressão das produções de pastagam sobre o fósforo.

\section{RESULTADOS DA SIMULAÇÃo}

Os procedimentos de previsão da produção de pastagem, a partir dos nutrientes do so. lo com os efeitos do ano resultantes das invasões de ervas daninhas discutidos aqui, foram incorporados em simulações por computador os quais têm sido usados não só como uma parte do modelo completo para estimativa da capacidade de suporte em uma parte da rodovia Transamazônica (Fearnside, 1978), mas também como simulações separadas apenas de produções de gado. As mudanças que acon- 
tecem no solo sob pastagem (Fearnside, s/d b) estão incluídas também nas mesmas simulações. A produçăo de capim é convertida em $\mathrm{kg}$ de peso vivo adquirido pelo gado bovino

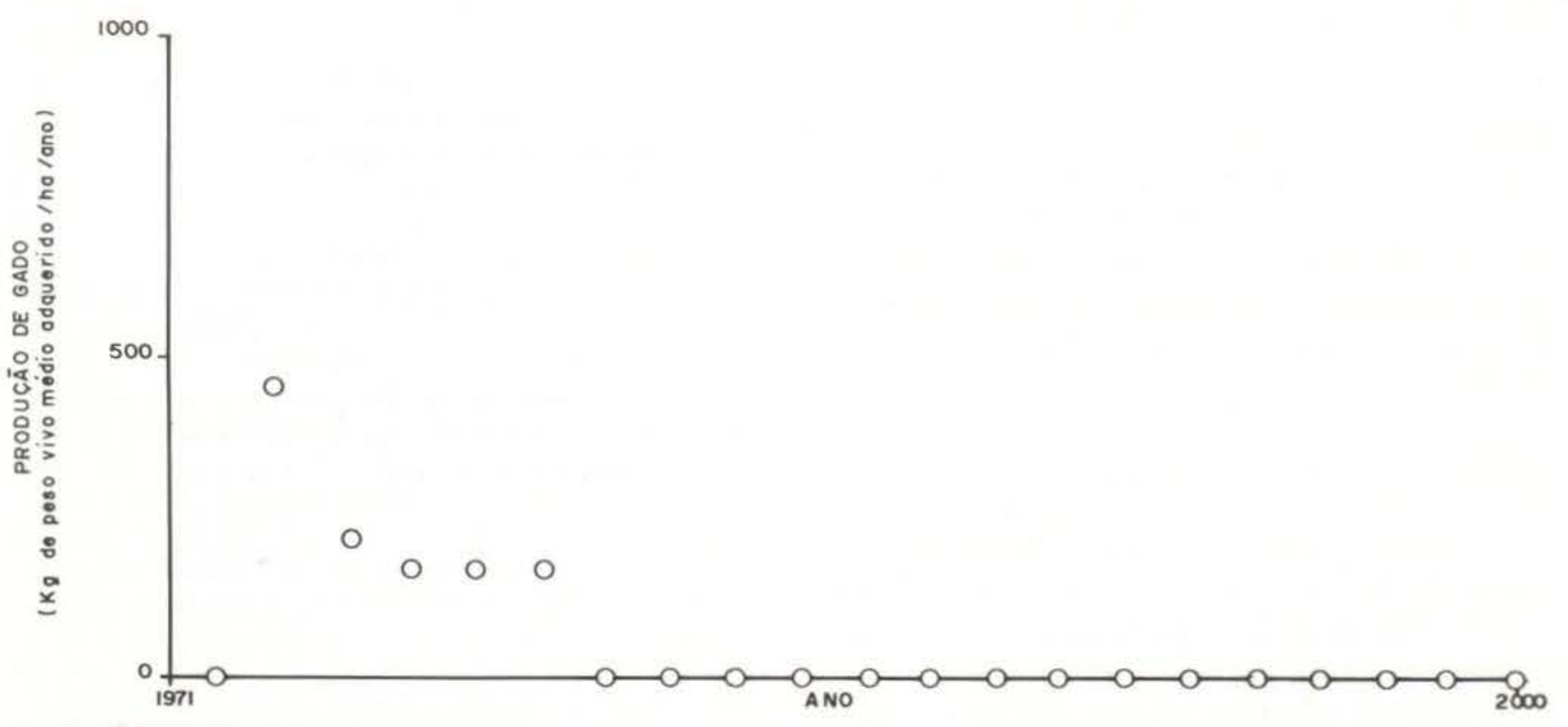

Fig. 2 - As produçōes de gado a partir da simulaçăo AGRISIM. As produçōes são expressadas em kg de peso vivo adquirido pelo gado, por hectare, por ano. As produçōes declinam bastante devido à invasāo de ervas daninhas .

Deve se tomar cuidado na interpretação de resultados simulados, como os apresentados na figura 2, porque tais resultados não pretendem representar projeções de produções em anos determinados. Os anos apresentados na figura pretedem somente orientar o leitor a respeito do horizonte de tempo usado na simulação.

O forte declínio nas produçōes de gado. indicadas pela figura 2 , é o resultado da invasão da pastagem pelas ervas daninhas. Se os efeitos das ervas daninhas fossem arbitrariamente excluídos das simulaçōes, o resultado seria uma produção constante a níveis perto das produçōes do primeiro ano da figura 2. Os baixos níveis de fósforo do solo restringiram o crescimento do capim, resultando em produções de gado substancialmente abaixo das projeções oficiais, mesmo que se deixe de lado os efeitos das ervas daninhas. Entretanto, os efeitos das ervas daninhas não podem ser deixados de lado no mundo real. Diversas suposições, inerentes na simulação, tais como: que o gado consome todo o capim produzido e que o fazendeiro mantém a taxa de lotação por por ano. Os resultados de uma execução de terminística do programa AGRISIM simulando produções de gado, são apresentados na figura 2. 
dos fatores de conversão para converter os pesos secos do capim em aquisiçăo de crescimento do gado, e das informações sobre os efeitos das ervas invasoras na pastagem. Muitas afirmações de alta "capacidade de suporte" da pastagem na Amazônia brasileira são baseadas em observações a curto prazo das taxas de lotação ao invés de informação que indicasse sustentabilidade a longo prazo. Uma simulação, incorporando tanto ervas daninhas quanto efeitos do solo, fornece razão séria para duvidarmos do potencial da pastagem para fornecer as produções sustentáveis que os planejadores atualmente antecipam.

\section{AgRADECIMENTOS}

A lista de pessoas e instituições merecedores de agradecimentos, pela ajuda durante a execução do projeto do qual o presente artigo é uma parte, é muito maior do que a aqui mencionada. Os colonos da rodovia Transamazônica são os primeiros. $\mathrm{O} \mathrm{Dr}$. Paulo $\mathrm{E}$. Vanzolini merece agradecimento especial pela ajuda e encorajamento desde o começo de meu trabalho no Brasil. O Centro de Pesquisas Agropecuárias do Trópico Úmido da EMBRAPA merece agradecimentos pelo apoio logístico, bem como pelas análises químicas das amostras do solo. O Instituto Nacional de Colonização e Reforma Agrária, a Empresa Brasileira de Assistência Técnica e Extensão Rural, e - Museu Paraense Emílio Goeldi, merecem reconhecimento pelo apoio logístico durante o trabalho de campo. Verbas para várias partes do projeto vieram da National Science Foundation Dissertation Improvement Grant GS-42869, de uma bolsa de pre-doutorado da Resources for the Future, duas bolsas do Institute for Environmental Quality, a Universidade de Michigan, e o Programa do Trópico Úmido do Conselho Nacional de Desenvolvimento Científico e Tecnológico. Nenhuma das posições expressadas neste trabalho são de responsabilidade das organizações que financiaram o projeto. O mesmo pode ser dito para as muitas pessoas que, tanto no Brasil como nos Estados Unidos, discutiram e comentaram o projeto. Agradeço a todas elas. Todos os erros de interpretação, se houverem, são exclusivamente de minha responsabilidade.

\section{SUMMARY}

The Brazilian government is presently encouraging the rapid development of cattle pasture in large parts of the Amazon Basin through a massive program of $\mathrm{fi}$ nancial and tax incentives. This has heen encouraged by recent claims in Brazil that pasture improves soil quality, and therefore presumably could supply an indefinite yield of cattle to the ranchers that are responding to the incentives program. Calculation of beef productivity to be expected in areas such as Brazil's Transamazon Highway by a variety of means all lead to the conclusion that government expectations are overoptimistic. The present paper develops equations for prediction of cattle yields for a study area on the Transamazon Highway including the effects of both soil nu trients and competition from weeds. Low levels of soil phosphorus and invasion of inedible weeds soon reduce grass and cattle yields to very low levels. Results of a computer simulation of cattle yields based on the relationships developed linking yields to soil nutrients and weeds, and on the soil information gathered in the Transamazon Highway study area, are presented. The pasture simulation forms a part of a larger simulation of the agroecosystem of the Transamazon Highway colonists which is aimed at assessing the importance of various factors on the carrying capacity of the area for human populations. Although the carrying capacity study shows that agriculture based largely on annual crops is a risky business, it also casts doubt on the presumption of secure and sustainable yeilds from the pasture development schemes currently being promoted in the Brazilian Amazon.

\section{BIBLIOGRAFIA}

Barcelos, J. M.

1974 - Subsídios e diretrizes para um programa de pesquisa com bovinocultura na regiâo norte: in Reunião do Grupo Interdisciplinar de Trabalho sobre Diretrizes de Pesquisa Agrícola para a Amazônia (Trópico Úmido), Brasilia, Maio $6-10,1974$. Empresa Brasileira de Pesquisa Agropecuária, (Brasília, EMBRAPA) Vol. 2: $6.1-6.55$.

BRASIL, INSTITUTO do DESENYOLVIMENTO

ECONÔMICO-SOCIAL DO PARÁ (IDESP)

1970 - Evolução e Características da Pecuária no Estado do Pará, (Belém, IDESP).

Falesi, I. C.

1974 - O solo na Amazônia e sua relação com a definição de sistemas de produção agrícola; in Região do Grupo Interdisciplinar de Trabalho sobre Diretrizes de Pesquisa Agrí. cola para a Amazônia (Trópico Úmido), Brasília, Maio 6-10, 1974. Empresa Brasileira de Pesquisa Agropecuária, (Brasilia, EMBRAPA) Vol. 1: $2.1-2.17$. 
1976 - Ecossistema de Pastagem Cultivada na Amazônia Brasileira, Boletim Técnico do Centro de Pesquisas Agropecuária do Tró. pico Úmido (CPATU) N. 1, (Belém, CPATU) $193 \mathrm{pp}$.

FEARNSIDE, P. M.

1978 - Estimation of Carryng capacity for Human Populations in a part of the Transamazon Highway Colonization Area of Brasil. (University of Michigan Ph.D. dissertation in Biological Sciences, Ann Arbor, Michigan) University Microfilms, Ann Arbor, 624 p.

1979 - Cattle yield prediction for the Transamazon Highway of Brazil. Interciencia 4(4): 220-225.

s/da - A Simulação da Capacidade de Suporte para Populações Humanas nos Trópicos Úmidos: Programa de Computador e Do. cumentaçāo. (No prelo, INPA)

$\mathrm{s} / \mathrm{d} \mathbf{b}$ - Os efeitos das pastagens sobre a fertilidade do solo na Amazônia Brasileira: Conseqüências para a sustentabilidade de produção bovina. (No prelo. Acta Amazonica).

Food And Agriculture Organization (FAO)

1973 - Report of the ICP mission to Brazil : agroindustrial potential of legal Amazonia. Do. cument DDI G/73/53, Rome, UN-FAO 125 p.

KAMPRATH, E. J.

1973 - Phosphorus : in A Review of Soil Research in Tropical Latin America. P. A. Sanchez, Ed., Raleigh, North Carolina State University Soil Science Department: 135-161.

KLEIBER, M.

1961 - The Fire of Life. New York, John Wiley and Sons.

Koster, H. W.; Khan, E. J. A. \& Bosshart, R. P.

1977 - Programa e resultados preliminares dos estudos de pastagens na região de Paragominas, Pará, e nordeste de Mato Grosso, junho 1975 - dezembro 1976. Belém, Mi. nistério do Interior, Superintendência do Desenvolvimento da Amazônia, Departamen. to de Setores Produtivos, Convênio SUDAM/ Instituto de Pesquisas IRI, $31 \mathrm{p}$.

Nascimento, C.N.B. do \& Moura Carvalho, L.O.D. de

1973 - Informaçōes de aspectos pecuários brasileiro; in Reunion Técnica de Programacion sobre Desarrollo Ganadero de Trópico Humedo Americano, Guyaquil; Equador, Diciembre 10-14, 1973. Informe de Conferencias, Cursos y Reuniones N. 30 , Instituto Interamericano de Ciências Agrícolas de la OEA, (Belém, IICA-TRÓPICOS) III-B-1. III-B-57.
NORTH CAROLINA SATTE UNIVERSITY.

SOIL SCIENCE DEPARTMENT

1974 - Agronomic-Economic Research on Tropica! Soils, N.C.S.U. Soil Science Department Annual Report for 1974, Raleigh, North Carolina, N.C.S.U. Soil Science Department, $230 \mathrm{p}$.

ODUM, H. T.

1971 - Environment, Power and Society, New York. John Wiley and Sons, $331 \mathrm{p}$.

Serrão, E. A. S. \& Simão Neto M.

1971 - Informaçôes sobre duas espécies de gra mineas forrageiras do gênero Brachiaria na Amazônia : B. decumbens Stapf. e B. ruziziensis Germain et Everard. Instituto de Pesquisa Agropecuária do Norte (IPEAN) Série: Estudos sobre Forrageiras na Amazônia, $1(1)$ : $31 \mathrm{p}$.

Serrâo, E. A. S.; Cruz, E. de S.; Simño Neto M.;

Sousa, G. F. de; Bastos, J. B. \& Guimarães, M. C. de F.

1971 - Resposta de três gramineas forrageiras (Brachiaria decumbens Stapf., Brachiaria ruziziensis Germain et Everard e Pennisetum purpureum Schum.) a elementos fertilizen. tes em latosolo amarelo textura média.Instituto de Pesquisa Agropecuária do Norte (IPEAN) Série: Fertilidades do Solo, 1(2): 388.

Simão Neto, M.; Serrāo, E. A. S.; Gonçalves, G. A. \& PIMENTEL, D. M.

1973 - Comportamento de gramíneas forrageiras na regiāo de Belém. Comunicado Técnico $\mathrm{N}$. 44 do Instituto de Pesquisas Agropecuária do Norte, Belém, IPEAN, $19 \mathrm{p}$.

SмIтH, N.J.H.

1977 - Influências culturais e ecológicas na produtividade agrícola ao longo da Transama. zônica. Acta Amazonica, 7 (1): 23-38.

Sudam, Departamento DE INCENTIVos

1974 - Considerações sobre a pecuária na Amazô. nia (Documento preliminar apresentado ao IV SERAM-AGROPECUARIA-São Paulo - SP, - 04 a 08/02/74), SUDAM, São Paulo, 48 p.

VICENTE-CHANDLER, J,

1975 - Intensive management of pastures and forages in Puerto Rico; in Soil Management in Tropical America: Proceedings os a Seminar held at CIAT, Cali, Colombia, Februa. ry 10-14, 1974. E. Bornemisza \& A. Alvarado. Eds., Raleigh, North Carolina, North $\mathrm{Ca}$ rolina State University Soil Science Department, $409-452$. 
VIÉGAS, R. M. F. \& KAss, D. C. L.

1974 - Resultados de trabalhos experimentais na Transamazônica no período 1971 a $1974, \mathrm{Be}$ lém. Empresa Brasileira de Pesquisa Agropecuária-Instituto de Pesquisa Agropecuária do Norte (EMBRAPA-IPEAN) $54 \mathrm{p}$.

WATTERS, R. F.

1971 - Shifting Cultivation in Latin America, United Nations Food and Agriculture Organization Forestry Development Paper N.: 17, Ro. me, UN-FAO, 305 p.
Waugh, D. L.; Cate JR., R. B.; Nelson, L. A

\& manzano, A.

1975 - New concepts in biological and economical interpretation of fertilizer response; in Soil Management in Tropical America: Proceedings of a Seminar held at CIAT, Cali, Colombia, February 10-14, 1974. E. Bornemis. za and A. Alvarado, Eds., Raleigh, North Carolina, North Carolina State University Soil Science Department: $484-563$.

(Aceito para publicação em 20/07/79) 